\title{
Differential oxidative stress response in young children and the elderly following exposure to $\mathbf{P M}_{2.5}$
}

\author{
Kyoungwoo Kim · Eun-Young Park $\cdot$ Kwan-Hee Lee \\ Jung-Duck Park · Yong-Dae Kim · Yun-Chul Hong
}

Received: 29 July 2008/ Accepted: 6 October 2008/Published online: 8 November 2008

(C) The Japanese Society for Hygiene 2008

\begin{abstract}
s
Objectives The mechanism of the adverse health effects of ambient particulate matter on humans has not been wellinvestigated despite many epidemiologic association studies. Measurement of personal exposure to particulate pollutants and relevant biological effect markers are necessary in order to investigate the mechanism of adverse health effects, particularly in fragile populations considered to be more susceptible to the effects of pollutants.

Methods We measured personal exposure to $\mathrm{PM}_{2.5}$ and examined oxidative stress using urinary malondialdehyde three times in 51 preschoolers and 38 elderly subjects.
\end{abstract}

\section{K. Kim}

Department of Family Medicine, Inje University,

Seoul Paik Hospital, Seoul, South Korea

E.-Y. Park · Y.-C. Hong $(\bowtie)$

Department of Preventive Medicine, College of Medicine,

Seoul National University, 28 Yeongeon Dong,

Jongro Gu, Seoul 110-799, South Korea

e-mail: ychong1@snu.ac.kr

K.-H. Lee

Department of Occupational and Environmental Medicine,

Inha University Hospital, Incheon, South Korea

J.-D. Park

Department of Preventive Medicine, College of Medicine, Chung-Ang University, Seoul, South Korea

Y.-D. Kim

Department of Preventive Medicine, College of Medicine, Chungbuk National University, Cheongju, South Korea

\section{Y.-C. Hong}

Institute of Environmental Medicine,

Seoul National University

Medical Research Center, Seoul, South Korea
A linear mixed-effects model was used to estimate $\mathrm{PM}_{2.5}$ effects on urinary MDA levels.

Results Average personal exposure of the children and elderly to $\mathrm{PM}_{2.5}$ was $80.5 \pm 29.9$ and $20.7 \pm 12.7 \mu \mathrm{g} / \mathrm{m}^{3}$, respectively. Mean urinary MDA level in the children and the elderly was $3.6 \pm 1.9$ and $4.0 \pm 1.6 \mu \mathrm{mol} / \mathrm{g}$ creatinine. For elderly subjects the $\mathrm{PM}_{2.5}$ level was significantly associated with urinary MDA after adjusting for age, sex, BMI, passive smoking, day-care facility site, alcohol consumption, cigarette smoking, and medical history (heart disease, hypertension and bronchial asthma). However, there was no significant relationship for children.

Conclusions The elderly were more susceptible than young children to oxidative stress as a result of ambient exposure to $\mathrm{PM}_{2.5}$. Identification of oxidative stress induced by $\mathrm{PM}_{2.5}$ explains the mechanism of adverse health effects such as cardiovascular or respiratory diseases, particularly in the elderly.

Keywords Particulate matter - Oxidative stress . Repeated measurement · Malondialdehyde .

Biological markers

\section{Introduction}

Recent evidence from epidemiological studies has shown that air pollution is associated with adverse health effects such as an increase in cardiovascular and pulmonary disease [1-5]. In particular, increased risk of hospitalization for cardiovascular and pulmonary diseases has also been reported to be associated with particulate air pollution [6, 7]. However, most epidemiological studies have used outdoor central monitoring data as the exposure estimates, and evidence supporting relevant biological mechanisms of 
how ambient particulate matter causes adverse health effects is insufficient.

Although the pathophysiological mechanisms linking inhalation of air pollution to acute exacerbation of cardiovascular or pulmonary disease are not completely understood in humans, inflammation has been reported to be induced by particulate air pollution in several humanexposure studies, but it is uncertain whether oxidative stress is mediated by particle-induced inflammation [8, 9]. Although results from cell-culture and animal experiments suggest that oxidative stress is involved in its pathogenesis, evidence of the relationship between human exposure to ambient particulate matter and oxidative stress is still lacking $[10,11]$. This lack of clear understanding arises in part from the difficulty of measuring human exposure to ambient concentrations of pollutants and evaluating the resulting health effects. Monitoring personal exposure instead of using outdoor central monitoring data and utilizing relevant biomarkers instead of disease or mortality record could be one of the more precise methods for characterizing individual exposure and early effects, which are expected to explain their mechanisms.

Because people spend most of their time indoors, using outdoor environmental data to represent a subject's exposure may not be an accurate method of evaluating the effects of air pollution exposure [12]. In addition, different exposures are expected individually according to considerable spatial variations, various indoor sources and composition of ambient particulate pollutants, and different personal activity levels [13, 14]. Therefore, measuring personal exposure and its biological effects on an individual basis is an important issue in air pollution epidemiological studies.

Biomarkers can be used to relate exposure to biological effects such as oxidative stress, which is thought to be involved in the mechanisms of adverse health effects of particulate pollutants. We measured urinary malondialdehyde (MDA) concentrations in spot urine samples as a relevant biomarker representing oxidative stress, considering times between exposure and its biological effects. As for human biomarkers of oxidative stress, MDA, one of the aldehyde products of lipid peroxidation, is known to be an end-product of free radical reactions and elevated MDA levels are found in many diseases including cardiovascular disease and cancer $[15,16]$.

As for human exposure and oxidative damage, some studies regarding outdoor central monitoring data as exposure estimates in young subjects found a significant association between particulate air pollution and oxidative stress, but others found no association [17-19]. Recently, as measurement of personal exposure and issue of monitoring devices have progressed, researchers have shown associations between individual exposure to particulate pollutants and biomarkers of oxidative damage [20, 21]. Further, because populations susceptible to the effects of particulate matter could be identified by personal monitoring, it helps to determine target populations for air pollution control [22].

The primary objective of this study was to examine the link between exposure to fine particulate matter and oxidative stress, with the hypothesis that not all groups of people respond to particulate pollutant exposure in the same way. In particular, young children and the elderly were recruited for this study with the assumption that they have different susceptibility to oxidative stress induced by particulate air pollution.

\section{Methods}

\section{Participants}

A total of 38 elderly volunteers at two day-care facilities and 51 children in one kindergarten class in Seoul participated in this study. General information about sociodemographic factors, past medical history, and family history were acquired by means of interviews, and anthropometric measurements were obtained during the first visit. We also obtained smoking history (no smoking/ past smoking/current smoking) and alcohol consumption (no drinking/less than 2-3 times per month/1-2 times per week/3-4 times per week/almost daily) from the elderly participants. The ethical committee of the Seoul National University Hospital approved this study, and informed consent was obtained from each participant.

$\mathrm{PM}_{2.5}$ sampling and analysis

We measured personal exposure to $\mathrm{PM}_{2.5}$ of participating subjects at two day-care facilities for elderly and at a kindergarten for children. To account for temporal variation, the measurements were repeated three times in August, October, and December 2005 for the elderly participants and in October and December 2006 and February 2007 for the children.

The particles were sampled with a $\mathrm{PM}_{2.5}$ cyclon (Personal Environmental Monitor, SKC, USA) containing a pump (Mine Safety Appliances, USA), and a battery for $12 \mathrm{~h}$ operation. The air flow rate $(2 \mathrm{l} / \mathrm{min})$ of the pump was adjusted before each sampling. The $\mathrm{PM}_{2.5}$ cyclon was attached with a pin between the chest and head, and the pump was placed in a small bag that the subjects carried during measurement.

The suspended fine particles were sampled over $6 \mathrm{~h}$ for each subject. The $37 \mathrm{~mm}, 2.0 \mu \mathrm{m}$ Teflon filters (PTFE, USA) were weighed before and after sampling using a 
microbalance and the concentration of ambient particulate matter was calculated considering air flow and measurement time.

\section{Measurement of urinary MDA}

For each participant, $30 \mathrm{ml}$ urine was collected at each visit between 4:00 and 5:00 pm; these samples were kept frozen at $-70^{\circ} \mathrm{C}$ until analysis. Urinary MDA was determined by measurement of MDA-thiobarbituric acid (TBA) adducts. Aliquots of the upper layers of centrifuged urine samples were mixed with phosphoric acid and TBA reagent in an iced methanol glass tube, and the mixtures were boiled for $60 \mathrm{~min}$. After the mixture had been boiled it was cooled in ice water for $5 \mathrm{~min}$ and centrifuged after addition of methanol. The absorbance was measured by high-performance liquid chromatography (HPLC), using a system equipped with an SP930D solvent-delivery pump and a UV730D absorbance detector (Youngin, Korea). Compounds were separated on a Nova-Pak C18 column $(150 \times 3.9 \mathrm{~nm})$ with $50 \mathrm{mM}$ $\mathrm{KH}_{2} \mathrm{PO}_{4}$ (pH 6.8)-methanol 58:42 (v/v) as mobile phase. Detection was at $532 \mathrm{~nm}$.

\section{Statistical analysis}

Associations between exposure to $\mathrm{PM}_{2.5}$ and urinary MDA concentrations were assessed. A linear mixedeffects model was used to estimate the effects of pollutants on urinary MDA, controlling for age, sex, BMI, passive smoking, and measurement session. For the elderly, day-care facility site, alcohol consumption, cigarette smoking, and medical history (heart disease, hypertension, and bronchial asthma) were also included in the model. Because the distribution of urinary MDA concentrations was skewed, log-transformed data were used for these measurements in the linear-mixed models. Age, sex, height, weight, alcohol consumption, and smoking exposure were treated as fixed effects, whereas each subject was treated as a random effect in the models. Statistical analyses were conducted with SAS (version 9.1). All tests of statistical significance were two-sided ( $\alpha$-error 0.05).

\section{Results}

General characteristics of the study participants are shown in Table 1. Mean subject age was $5.9 \pm 0.2$ for the children and $78.6 \pm 6.0$ for the elderly. In this study population $72.5 \%$ of the preschoolers and $42.1 \%$ of the elderly were male; $39.5 \%$ of the elderly subjects were current smokers. In addition, $42.1 \%$ of the elderly reported the presence of hypertension. The proportion of subjects that had the heart disease and bronchial asthma were 7.9 and 5.3\% (not shown in Table 1).

Personal exposure to $\mathrm{PM}_{2.5}$ and concentrations of urinary MDA are shown in Table 2. The mean personal $\mathrm{PM}_{2.5}$ was $80.5 \pm 29.9 \mu \mathrm{g} / \mathrm{m}^{3}$ in the children and $20.7 \pm 12.7 \mu \mathrm{g} / \mathrm{m}^{3}$ in the elderly. However, the mean urinary MDA concentrations were not significantly different between two groups, with means of $3.6 \pm 1.9 \mu \mathrm{mol} / \mathrm{g}$ $\mathrm{cr}$ for the children and $4.0 \pm 1.6 \mu \mathrm{mol} / \mathrm{g} \mathrm{cr}$ for the elderly.

The relationship between personal exposure to $\mathrm{PM}_{2.5}$ and urinary MDA concentrations is shown in Fig. 1. The horizontal axis is the level of personal exposure to $\mathrm{PM}_{2.5}$ assessed over $6 \mathrm{~h}$ and the vertical axis is the log-transformed urinary concentration of MDA adjusted by urinary creatinine (cr) level from spot urine collected in three sessions from 51 preschoolers and 38 elderly subjects.

The mixed-effects model of log MDA concentration for personal $\mathrm{PM}_{2.5}$ exposure showed a statistically significant increase of $0.3 \% \log$ MDA concentration per $1 \mu \mathrm{g} / \mathrm{m}^{3}$ increase of personal $\mathrm{PM}_{2.5}$ exposure in the elderly. This study showed that estimates of change for urinary MDA concentrations attributable to personal $\mathrm{PM}_{2.5}$ exposure were quite different for children and the elderly. In children, the mixed-effects model of log MDA concentration for personal $\mathrm{PM}_{2.5}$ exposure showed no association between them, controlling for age, sex, BMI, passive smoking, and measurement session.

\section{Discussion}

This study found a significant association between fine particulate pollution and urinary MDA concentration in the elderly, but not in children, demonstrating that the elderly are more susceptible than young children to oxidative stress induced by ambient fine particulates.

We used personal exposure to $\mathrm{PM}_{2.5}$ as exposure variable. The mean personal $\mathrm{PM}_{2.5}$ was $80.5 \pm 29.9 \mu \mathrm{g} / \mathrm{m}^{3}$ for the children and $20.7 \pm 12.7 \mu \mathrm{g} / \mathrm{m}^{3}$ for the elderly subjects. Air monitoring data for ambient air pollutants in Seoul showed that annual mean values for $\mathrm{PM}_{10}$ were 58 and $60 \mu \mathrm{g} / \mathrm{m}^{3}$ in 2005 and 2006 [23]. Ambient $\mathrm{PM}_{2.5}$ concentrations were not monitored regularly in Seoul, but a report showed that 24-h means of outdoor and indoor $\mathrm{PM}_{2.5}$ were 56.0 and $43.2 \mu \mathrm{g} / \mathrm{m}^{3}$ [24].

Personal concentrations of $\mathrm{PM}_{2.5}$ may reflect the level of indoor $\mathrm{PM}_{2.5}$ rather than outdoor levels [14, 25]. However, despite the higher $\mathrm{PM}_{2.5}$ level in children, there is little difference in the oxidative stress concentrations between the elderly and the preschoolers. Urinary MDA concentrations in the elderly $(4.0 \mu \mathrm{mol} / \mathrm{g} \mathrm{cr})$ and in children 
Table 1 General characteristics of preschoolers and the elderly

${ }^{\text {a }}$ Number $(\%)$

${ }^{\mathrm{b}}$ Mean \pm standard deviation

\begin{tabular}{|c|c|c|c|c|c|c|}
\hline & \multicolumn{3}{|l|}{ Preschoolers } & \multicolumn{3}{|l|}{ The elderly } \\
\hline & Male & Female & Total & Male & Female & Total \\
\hline $\operatorname{Sex}^{\mathrm{a}}$ & $37(72.5)$ & $14(27.5)$ & 51 & $16(42.1)$ & $22(57.9)$ & 38 \\
\hline $\mathrm{Age}^{\mathrm{b}}$ & $6.0 \pm 0.2$ & $5.9 \pm 0.3$ & $5.9 \pm 0.2$ & $76.1 \pm 7.0$ & $80.6 \pm 4.3$ & $78.6 \pm 6.0$ \\
\hline Weight $(\mathrm{kg})^{\mathrm{b}}$ & $23.0 \pm 2.5$ & $22.5 \pm 3.2$ & $22.8 \pm 2.6$ & $61.4 \pm 8.9$ & $50.8 \pm 7.5$ & $55.4 \pm 9.6$ \\
\hline Height $(\mathrm{cm})^{\mathrm{b}}$ & $117.9 \pm 4.8$ & $117.9 \pm 5.6$ & $117.9 \pm 5.0$ & $162.9 \pm 6.3$ & $148.6 \pm 4.6$ & $154.8 \pm 8.9$ \\
\hline Current smoker ${ }^{\mathrm{a}}$ & & & & $12(75.0)$ & $3(13.6)$ & $15(39.5)$ \\
\hline $\begin{array}{l}\text { Frequent drinker }(\geq 3- \\
\quad 4 \text { times/week })^{\mathrm{a}}\end{array}$ & & & & $5(31.3)$ & $0(0)$ & $5(13.2)$ \\
\hline
\end{tabular}

Table 2 Mean concentrations of personal $\mathrm{PM}_{2.5}$ and urinary MDA for the preschoolers in October and December 2006 and February 2007 , and for the elderly in August, October, and December 2005

\begin{tabular}{|c|c|c|c|c|c|c|c|c|}
\hline & \multicolumn{4}{|l|}{ Preschoolers } & \multicolumn{4}{|l|}{ The elderly } \\
\hline & October & December & February & Mean & August & October & December & Mean \\
\hline $\begin{array}{l}\mathrm{PM}_{2.5} \\
\quad\left(\mu \mathrm{g} / \mathrm{m}^{3}\right)^{\mathrm{a}}\end{array}$ & $80.48 \pm 25.46$ & $81.45 \pm 28.57$ & $79.41 \pm 35.66$ & $80.46 \pm 29.92$ & $17.72 \pm 11.72$ & $22.82 \pm 12.56$ & $21.46 \pm 13.49$ & $20.67 \pm 12.66$ \\
\hline $\begin{array}{l}\text { MDA } \\
\qquad(\mu \mathrm{mol} / \mathrm{g} \\
\mathrm{Cr})^{\mathrm{b}}\end{array}$ & $3.70 \pm 2.02$ & $4.35 \pm 2.04$ & $2.93 \pm 1.66$ & $3.61 \pm 1.94$ & $4.30 \pm 1.75$ & $3.94 \pm 1.50$ & $3.80 \pm 1.51$ & $4.02 \pm 1.60$ \\
\hline
\end{tabular}

${ }^{a}$ Mean \pm standard deviation

${ }^{\mathrm{b}}$ Geometric mean \pm geometric standard deviation

Fig. 1 Relationship between personal exposure to $\mathrm{PM}_{2.5}$ assessed over $6 \mathrm{~h}$ and urinary MDA concentrations measured three times for 51 preschool children (a) and 38 elderly subjects (b)
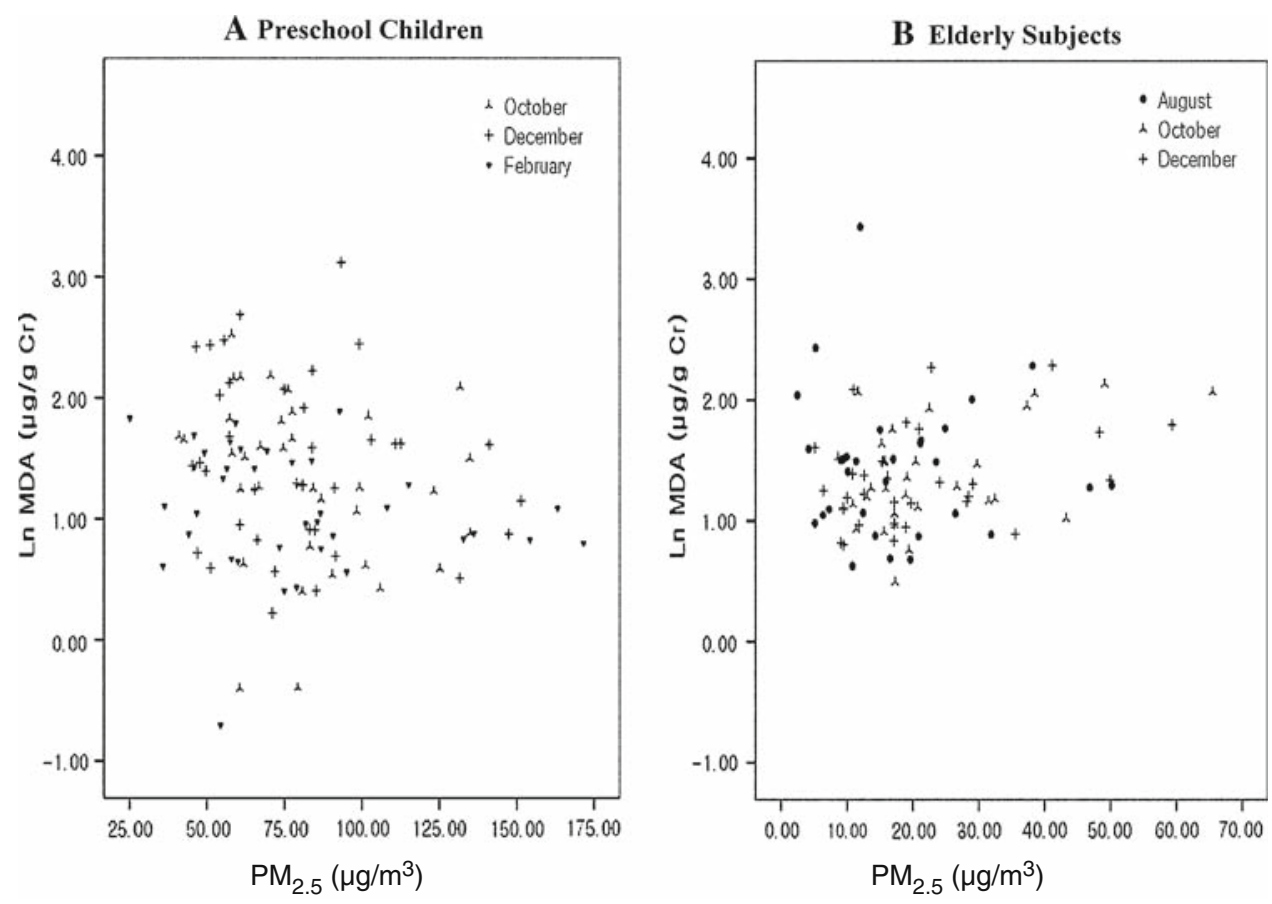

\begin{tabular}{|l|l|l|l|l|}
\hline \multirow{2}{*}{} & \multicolumn{2}{|l|}{ Preschoolers $^{\mathrm{a}}$} & \multicolumn{2}{l|}{ The elderly $^{\mathrm{b}}$} \\
\cline { 2 - 5 } & Log MDA_Cr & \multicolumn{2}{l|}{ Log MDA_Cr } \\
\cline { 2 - 5 } & Coefficient & $P$ & Coefficient & $P$ \\
\hline $\mathrm{PM}_{2.5}$ & -0.00452 & 0.1249 & 0.0033 & 0.0225 \\
\hline
\end{tabular}

${ }^{a}$ Fixed effect : sex, BMI, passive smoking; random effect: person

${ }^{\mathrm{b}}$ Fixed effect : facility site, time, age, sex, alcohol, BMI, smoking, passive smoking, medical history (heart disease, hypertension, and bronchial asthma); Random effect: person 
( $3.6 \mu \mathrm{mol} / \mathrm{g}$ cr) in this study were comparable with the levels of MDA in asthmatic children under stable conditions $(3.0 \mu \mathrm{mol} / \mathrm{g} \mathrm{cr})$ and during asthma attacks $(4.4 \mu \mathrm{mol} /$ $\mathrm{g}$ cr) [26].

Mechanisms by which the particulate matter induces oxidative stress have been investigated in cell and animal experiments. Soluble transition metals and organic molecules adsorbed on to the surface of particles are capable of generating reactive oxygen intermediates in lung cells and activating redox-sensitive transcription factors to enhance inflammatory reactions [27]. Moreover, soluble constituents of $\mathrm{PM}_{2.5}$ that can cross the pulmonary epithelium into the circulation may directly affect the cardiovascular system via imbalance of the autonomic nervous system, systemic oxidative stress, and inflammatory response [28].

The production of reactive oxygen species and subsequent biomolecular damage can be repaired or removed by defense systems in normal metabolism. Therefore, the balance between production and degradation of reactive oxygen metabolites determines oxidative stress and health effects $[29,30]$. However, the functional capacity of antioxidant defense may be reduced with aging; aging is, therefore, a contributing factor for induction of oxidative stress [31, 32]. This mechanism was supported by the results of our study, which showed that exposure to particulate matter significantly produced metabolites of oxidative stress in the aged group, regarded as more vulnerable to oxidative stress, than in the young children group.

Biological markers are useful in explaining pathogenic mechanisms and recognizing early effects before development of disease. Therefore, through personal monitoring of exposure to particulate matter and use of biomarkers, it is possible to characterize individual exposure and explore the mechanisms leading to relevant biological effects [33]. Sørensen et al. [34] measured personal exposure to $\mathrm{PM}_{2.5}$ and 8-oxodG in the blood and urine of students in Copenhagen, and found that personal $\mathrm{PM}_{2.5}$ exposure was associated with 8-oxodG concentrations in lymphocyte DNA, but not in urine.

MDA used as biomarker of oxidative stress in this study is known to be associated with many diseases including cardiovascular disease, cancer, Alzheimer's disease, liver disease, and adverse pregnancy outcomes [35-40]. There are numerous factors that are known to affect the formation of lipid peroxides. The level of MDA may be associated with age, body mass index and dietary factors. The consumption of some vegetables may have an inverse association with MDA concentration [41, 42]. On the other hand, alcohol and meat consumption and smoking behavior may increase the level [42]. In statistical analysis, we considered these factors and determined the final model including alcohol consumption, BMI, smoking behavior, passive smoking, and medical history (heart disease, hypertension, and bronchial asthma).

Elderly people spend most of their time indoors and personal exposure to $\mathrm{PM}_{2.5}$ does not correlate strongly with outdoor central site $\mathrm{PM}_{2.5}$ concentrations [14]. Sources of indoor ambient particles are not only from outdoor contributions, but also from indoor sources such as smoking, cooking, combustion, indoor resuspension of dusts by human activities, and transformation processes [43, 44]. To reduce errors in the measurement and bias of the exposureeffect relationship, we repeatedly measured personal exposure instead of using outdoor or indoor area monitoring data as an exposure estimate.

In this study, personal exposure to $\mathrm{PM}_{2.5}$ was four times higher for the children than for the elderly. Personal exposure to $\mathrm{PM}_{2.5}$ has been reported to be associated with activities such as walking or cycling and proximity to microenvironments [45]. Therefore, assuming the indoor and outdoor environments were not so different between two subgroups, but the elderly at day-care facilities are relatively inactive compared with the preschoolers in kindergarten, the reason for the differences in personal exposure level to $\mathrm{PM}_{2.5}$ may be resuspension of particulate matter and more particle collection in the filter because of the greater physical activity of the preschool children.

We found that the elderly are at a higher risk of oxidative stress associated with fine particulate pollutant exposure compared with children. Ambient concentrations of particles may be sufficient to cause oxidative stress in elderly subjects with compromised defense mechanisms against the attack of oxygen-containing free radicals, whereas young children will be able to tolerate higher exposure levels. However, it is unclear whether elderly people are more vulnerable to the effects of all components in the air pollution mixture. When studying associations between particulate matter and oxidative stress other considerations must be included, for example concomitant personal exposure to other pollutants, e.g. ozone, nitrous oxides, polycyclic aromatic hydrocarbons, heavy metals, and volatile organic chemicals.

In conclusion, the association between personal exposure to fine particulates and oxidative stress markers suggests that oxidative stress may be involved in the disease processes induced by particulate air pollution. This result explains the link between toxicological mechanisms in in-vitro experiments on particulate exposure and epidemiological evidence of particulate air pollution. This finding also suggests the need for air pollution-management policies to focus on susceptible populations, particularly the elderly. 
Acknowledgments This study was supported by the Eco-technopia 21 project of the Korea Institute of Environmental Science and Technology.

\section{References}

1. Pope CA 3rd, Burnett RT, Thurston GD, Thun MJ, Calle EE, Krewski D, et al. Cardiovascular mortality and long-term exposure to particulate air pollution: epidemiological evidence of general pathophysiological pathways of disease. Circulation. 2004;109:71-7.

2. Alfaro-Moreno E, Nawrot TS, Nemmar A, Nemery B. Particulate matter in the environment: pulmonary and cardiovascular effects. Curr Opin Pulm Med. 2007;13:98-106.

3. Pino P, Walter T, Oyarzun M, Villegas R, Romieu I. Fine particulate matter and wheezing illnesses in the first year of life. Epidemiology. 2004;15:702-8.

4. Sarnat JA, Schwartz J, Suh HH. Fine particulate air pollution and mortality in 20 U.S. cities. N Engl J Med. 2001;344:1253-4.

5. Wellenius GA, Bateson TF, Mittleman MA, Schwartz J. Particulate air pollution and the rate of hospitalization for congestive heart failure among medicare beneficiaries in Pittsburgh, Pennsylvania. Am J Epidemiol. 2005;161:1030-6.

6. Dominici F, Peng RD, Bell ML, Pham L, McDermott A, Zeger SL, et al. Fine particulate air pollution and hospital admission for cardiovascular and respiratory diseases. JAMA. 2006;295:1127-34.

7. Lee JT, Son JY, Cho YS. The adverse effects of fine particle air pollution on respiratory function in the elderly. Sci Total Environ. 2007;385:28-36.

8. Ghio AJ, Kim C, Devlin RB. Concentrated ambient air particles induce mild pulmonary inflammation in healthy human volunteers. Am J Respir Crit Care Med. 2000;162:981-8.

9. Ruckerl R, Ibald-Mulli A, Koenig W, Schneider A, Woelke G, Cyrys $\mathrm{J}$, et al. Air pollution and markers of inflammation and coagulation in patients with coronary heart disease. Am J Respir Crit Care Med. 2006;173:432-41.

10. Zeka A, Sullivan JR, Vokonas PS, Sparrow D, Schwartz J. Inflammatory markers and particulate air pollution: characterizing the pathway to disease. Int J Epidemiol. 2006;35:1347-54.

11. Salvi S, Holgate ST. Mechanisms of particulate matter toxicity. Clin Exp Allergy. 1999;29:1187-94.

12. Sexton K, Adgate JL, Ramachandran G, Pratt GC, Mongin SJ, Stock $\mathrm{TH}$, et al. Comparison of personal, indoor, and outdoor exposures to hazardous air pollutants in three urban communities. Environ Sci Technol. 2004;38:423-30.

13. Jantunen M, Hanninen O, Koistinen K, Hashim JH. Fine PM measurements: personal and indoor air monitoring. Chemosphere. 2002;49:993-1007.

14. Turpin BJ, Weisel CP, Morandi M, Colome S, Stock T, Eisenreich S, et al. Relationships of Indoor, Outdoor, and Personal Air (RIOPA): part II. Analyses of concentrations of particulate matter species. Res Rep Health Eff Inst. 2007;1-77; discussion 79-92.

15. Tagesson C, Kallberg M, Wingren G. Urinary malondialdehyde and 8-hydroxydeoxyguanosine as potential markers of oxidative stress in industrial art glass workers. Int Arch Occup Environ Health. 1996;69:5-13.

16. Bahcecioglu IH, Yalniz M, Ilhan N, Ataseven H, Ozercan IH. Levels of serum vitamin A, alpha-tocopherol and malondialdehyde in patients with non-alcoholic steatohepatitis: relationship with histopathologic severity. Int $\mathrm{J}$ Clin Pract. 2005;59:318-23.

17. Loft S, Poulsen HE, Vistisen K, Knudsen LE. Increased urinary excretion of 8-oxo-2'-deoxyguanosine, a biomarker of oxidative DNA damage, in urban bus drivers. Mutat Res. 1999;441:11-9.
18. Sram RJ, Binkova B. Molecular epidemiology studies on occupational and environmental exposure to mutagens and carcinogens, 1997-1999. Environ Health Perspect. 2000; 108(Suppl 1):57-70.

19. Piperakis SM, Petrakou E, Tsilimigaki S. Effects of air pollution and smoking on DNA damage of human lymphocytes. Environ Mol Mutagen. 2000;36:243-9.

20. Liu L, Ruddy TD, Dalipaj M, Szyszkowicz M, You H, Poon R, et al. Influence of personal exposure to particulate air pollution on cardiovascular physiology and biomarkers of inflammation and oxidative stress in subjects with diabetes. J Occup Environ Med. 2007;49:258-65.

21. Sorensen M, Autrup H, Hertel O, Wallin H, Knudsen LE, Loft S. Personal exposure to PM2.5 and biomarkers of DNA damage. Cancer Epidemiol Biomarkers Prev. 2003;12:191-6.

22. Mar TF, Koenig JQ, Jansen K, Sullivan J, Kaufman J, Trenga $\mathrm{CA}$, et al. Fine particulate air pollution and cardiorespiratory effects in the elderly. Epidemiology. 2005;16:681-7.

23. Korea MoEo. Environmental statistics yearbook. Ministry of Environment of Korea. 2007

24. Park JY, Seo HK. The relationship between indoor and outdoor PM10, PM2.5 concentrations in residential houses and respiratory symptoms. Indoor Environ Technol. 2005;1:228-35.

25. Crist KC, Liu B, Kim M, Deshpande SR, John K. Characterization of fine particulate matter in Ohio: indoor, outdoor, and personal exposures. Environ Res. 2008;106:62-71.

26. Leem JH, Kim JH, Lee KH, Hong Y, Kang D, Kwon HJ. Asthma attack associated with oxidative stress by exposure to ETS and PAH. J Asthma. 2005;42:463-7.

27. Meyer M, Pahl HL, Baeuerle PA. Regulation of the transcription factors NF-kappa B and AP-1 by redox changes. Chem Biol Interact. 1994;91:91-100.

28. Brook RD. Cardiovascular effects of air pollution. Clin Sci (Lond). 2008;115:175-87.

29. Frisard M, Ravussin E. Energy metabolism and oxidative stress: impact on the metabolic syndrome and the aging process. Endocrine. 2006;29:27-32.

30. Furukawa S, Fujita T, Shimabukuro M, Iwaki M, Yamada Y, Nakajima $\mathrm{Y}$, et al. Increased oxidative stress in obesity and its impact on metabolic syndrome. J Clin Invest. 2004;114:1752-61.

31. Yu BP. Aging and oxidative stress: modulation by dietary restriction. Free Radic Biol Med. 1996;21:651-68.

32. Yu BP, Yang R. Critical evaluation of the free radical theory of aging. A proposal for the oxidative stress hypothesis. Ann N Y Acad Sci. 1996;786:1-11.

33. Bateson TF, Schwartz J. Who is sensitive to the effects of particulate air pollution on mortality? A case-crossover analysis of effect modifiers. Epidemiology. 2004;15:143-9.

34. Sorensen M, Daneshvar B, Hansen M, Dragsted LO, Hertel O, Knudsen L, et al. Personal PM2.5 exposure and markers of oxidative stress in blood. Environ Health Perspect. 2003; 111:161-6.

35. Polidori MC, Savino K, Alunni G, Freddio M, Senin U, Sies H, et al. Plasma lipophilic antioxidants and malondialdehyde in congestive heart failure patients: relationship to disease severity. Free Radic Biol Med. 2002;32:148-52.

36. Gonenc A, Ozkan Y, Torun M, Simsek B. Plasma malondialdehyde (MDA) levels in breast and lung cancer patients. J Clin Pharm Ther. 2001;26:141-4.

37. Bakan E, Taysi S, Polat MF, Dalga S, Umudum Z, Bakan N, et al. Nitric oxide levels and lipid peroxidation in plasma of patients with gastric cancer. Jpn J Clin Oncol. 2002;32:162-6.

38. Delibas N, Ozcankaya R, Altuntas I. Clinical importance of erythrocyte malondialdehyde levels as a marker for cognitive deterioration in patients with dementia of Alzheimer type: a repeated study in 5-year interval. Clin Biochem. 2002;35:137-41. 
39. Kim YJ, Hong YC, Lee KH, Park HJ, Park EA, Moon HS, et al. Oxidative stress in pregnant women and birth weight reduction. Reprod Toxicol. 2005;19:487-92.

40. Yoneyama Y, Sawa R, Suzuki S, Doi D, Yoneyama K, Otsubo Y, et al. Relationship between plasma malondialdehyde levels and adenosine deaminase activities in preeclampsia. Clin Chim Acta. 2002;322:169-73.

41. Leuratti C, Watson MA, Deag EJ, Welch A, Singh R, Gottschalg E, et al. Detection of malondialdehyde DNA adducts in human colorectal mucosa: relationship with diet and the presence of adenomas. Cancer Epidemiol Biomarkers Prev. 2002;11:267-73.

42. Del Rio D, Stewart AJ, Pellegrini N. A review of recent studies on malondialdehyde as toxic molecule and biological marker of oxidative stress. Nutr Metab Cardiovasc Dis. 2005;15:316-28.
43. Branis M, Rezacova P, Domasova M. The effect of outdoor air and indoor human activity on mass concentrations of $\mathrm{PM}(10)$, $\operatorname{PM}(2.5)$, and PM(1) in a classroom. Environ Res. 2005;99:143-9.

44. Lazaridis M, Aleksandropoulou V, Smolik J, Hansen JE, Glytsos $\mathrm{T}$, Kalogerakis N, et al. Physico-chemical characterization of indoor/outdoor particulate matter in two residential houses in Oslo, Norway: measurements overview and physical propertiesURBAN-AEROSOL Project. Indoor Air. 2006;16:282-95.

45. Brauer M, Hirtle RD, Hall AC, Yip TR. Monitoring personal fine particle exposure with a particle counter. J Expo Anal Environ Epidemiol. 1999;9:228-36. 